\title{
O uso da rede social Tik Tok: uma estratégia interativa para o despertar da leitura
}

\author{
The use of the Tik Tok social network: an interactive strategy to awaken reading \\ El uso de la red social Tik Tok: una estrategia interactiva para el despertar de la lectura
}

Recebido: 27/09/2021 | Revisado: 05/10/2021 | Aceito: 06/10/2021 | Publicado: 10/10/2021

\author{
Luma Kathyn Silva Policarpo \\ ORCID: https://orcid.org/0000-0003-1919-8363 \\ Universidade de Cuiabá, Brasil \\ E-mail: lummapolicarpo@gmail.com \\ Lucy Ferreira Azevedo \\ ORCID: https://orcid.org/0000-0002-7072-3859 \\ Universidade de Cuiabá, Brasil \\ E-mail: lucyfazevedo@gmail.com \\ Simone Ribeiro Matos \\ ORCID: https://orcid.org/0000-0002-4397-2024 \\ Universidade de Cuiabá, Brasil \\ E-mail: simone_rbr12@hotmail.com
}

\begin{abstract}
Resumo
As TICs têm sido bem aceitas pelos estudantes da escola básica, porém nem sempre o professor está preparado para incentivar e construir esse tipo de trabalho. Diante da dificuldade de conviver com a nova linguagem, questiona-se sobre a base teórica e força da ferramenta vídeo para incentivo da produção de texto. Vivencia-se hoje um momento oportuno já que o documento de referência, a Base Nacional Comum Curricular - BNCC- orienta e recomenda um ensino interacionista e o uso da TDICs, além de outro reforço, a pandemia, que incitou o corpo docente da educação básica a reaprender tecnologias digitais e a mídia na área de Linguagens e suas Tecnologias. O objetivo, pois, é sugerir aos professores mais uma opção / ferramenta para o ensino de Língua Portuguesa em que se possa trabalhar com turmas do ensino médio com foco na disseminação de indicações de livros feitos pelos próprios alunos, vídeos esses produzidos por eles de forma dinâmica que traz o interesse e o despertar a leitura através das recomendações feitas. A pesquisa se ancora na metodologia qualitativa, de cunho bibliográfico, com aporte teórico na BNCC (2018), Rojo (2009;2012;2016;2019), Antunes (2003,2007), Ana Elisa Ribeiro (2007;2013), entre outros que discorrem sobre a temática. Os diálogos produzidos entre os professores devem contribuir para dias melhores e produtivos em sala de aula na escola básica.
\end{abstract}

Palavras-chave: Ensino; Leitores; Letramento literário.

\begin{abstract}
TICs have been well accepted by elementary school students, but the teacher is not always prepared to encourage and build this type of work. Faced with the difficulty of living with the new language, questions are raised about the theoretical basis and strength of the video tool to encourage text production. Today we are experiencing an opportune moment since the reference document, the Common National Curriculum Base - BNCC - guides and recommends an interactionist teaching and the use of TDICs, in addition to another reinforcement, the pandemic, which incited the teaching staff of basic education to relearn digital technologies and the media in the area of Languages and their Technologies. The objective, therefore, is to suggest to teachers one more option / tool for teaching Portuguese Language in which they can work with high school classes focusing on the dissemination of indications of books made by the students themselves, videos that they produce in a way dynamic that brings interest and awakens the reading through the recommendations made. The research is based on the qualitative methodology, of bibliographic nature, with theoretical support in BNCC (2018), Rojo (2009;2012;2016;2019), Antunes (2003,2007), Ana Elisa Ribeiro $(2007 ; 2013)$, among others that discuss the theme. The dialogues produced between teachers should contribute to better and productive days in the classroom at the elementary school.
\end{abstract}

Keywords: Teaching; Readers; Literary literacy.

\section{Resumen}

Las TICs han sido bien aceptadas por los estudiantes de primaria, pero el profesor no siempre está preparado para incentivar y construir este tipo de trabajo. Ante la dificultad de convivir con el nuevo idioma, se plantean interrogantes sobre la base teórica y la fortaleza de la herramienta de video para incentivar la producción de textos. Hoy vivimos un momento oportuno ya que el documento de referencia, la Base Curricular Nacional Común - BNCC - orienta y recomienda una enseñanza interaccionista y el uso de los TDICs, además de otro refuerzo, la pandemia, que incitó al profesorado de educación básica a reaprender las tecnologías digitales y los medios de comunicación en el área de 
Idiomas y sus Tecnologías. El objetivo, por tanto, es sugerir a los profesores una opción / herramienta más para la enseñanza de la Lengua Portuguesa en la que puedan trabajar con las clases de bachillerato enfocándose en la difusión de indicaciones de libros elaborados por los propios alumnos, videos que ellos producen de forma dinámica que atrae interés y despierta la lectura a través de las recomendaciones realizadas. La investigación se basa en la metodología cualitativa, de carácter bibliográfico, con sustento teórico en BNCC (2018), Rojo (2009; 2012; 2016; 2019), Antunes $(2003,2007)$, Ana Elisa Ribeiro $(2007$; 2013), entre otros que discuten el tema. Los diálogos producidos entre los profesores deben contribuir a mejores y productivos días en el aula de la escuela básica.

Palabras clave: Docencia; Lectores; Alfabetización literária.

\section{Introdução}

O uso de recursos tecnológicos no âmbito educacional está cada vez mais frequente, por isso é necessário utilizá-los a favor do corpo docente da educação básica. Além da pandemia que nos estimulou a lidar e aprender com esses meios, a Base Nacional Comum Curricular que é o documento atual discorre sobre tecnologias digitais da informação e comunicação, a famosa TDIC, por isso a oportunização de dialogar e propor novas ferramentas de ensino aos professores. Diante da dificuldade de conviver com a nova linguagem e aproveitá-la como mais um elemento de construção do saber, questiona-se sobre a base teórica e força da ferramenta vídeo para incentivo da produção de texto, porque ler e escrever são elementos fundamentais para o convívio em sociedade, por isso a escola tem como compromisso trabalhar a formação de novos letramentos, principalmente os digitais, já que estamos em uma era que os alunos são dominantes do assunto.

Além do mais, a BNCC apresenta algumas atualizações/orientações necessárias, tais como as aprendizagens essenciais definidas, em que os professores devem garantir o desenvolvimento das dez competências gerais, fora as das áreas de conhecimento que são específicas. Para a disciplina de Língua Portuguesa, existem os seguintes eixos de integração: oralidade, leitura/escuta, produção (escrita e multissemiótica) e análise linguística.

Diante deste cenário, a atual pesquisa busca inserir na vida estudantil práticas sociais do seu convívio para que possa auxiliar na aprendizagem, para esse fim foi escolhido o aplicativo TIK TOK, mídia social que possibilita a criação e o compartilhamento de vídeos curtos de no máximo sessenta segundos.

O objetivo é sugerir aos professores mais uma opção / ferramenta para o ensino de Língua Portuguesa em que se possa trabalhar com turmas do ensino médio com foco na disseminação de indicações de livros feitos pelos próprios alunos, vídeos esses produzidos por eles de forma dinâmica que traz o interesse e o despertar a leitura através das recomendações feitas. Indicar/apresentar aos professores mais uma opção de ferramenta para o ensino de Língua Portuguesa em que possa ser trabalhado com turmas do ensino médio com foco na disseminação de indicações de livros feitos pelos próprios alunos, vídeos esses produzidos por eles de forma dinâmica que traz o interesse e o despertar a leitura através das recomendações feitas é uma urgência, tendo-se em vista a transformação do professor analógico para o tecnológico sem apoio oficial.

Pensar, repensar e adaptar as estratégias no processo de ensino-aprendizagem é fundamental para uma melhoria da educação/ um ensino de qualidade, assim esse artigo trará uma proposta de incentivo à leitura através da plataforma midiática. A pesquisa se ancora na metodologia qualitativa, de cunho bibliográfico, com aporte teórico na BNCC (2018), Rojo (2009;2012;2016; 2019), Antunes (2003,2007), Ana Elisa Ribeiro (2007;2013), entre outros.

\section{Metodologia}

Ensinar e aprender são concomitantes na contemporaneidade, já que os estudantes estão sendo preparados para serem protagonistas da sua vida e os professores mediadores de ensino.

Têm-se como arcabouço teórico a BNCC (2018), Rojo (2009;2012;2016), Antunes (2003,2007), Ana Elisa Ribeiro (2007;2013), entre outros que discorrem sobre a temática. A metodologia eleita para a discussão é a metodologia qualitativa, de cunho bibliográfico, 
O enfoque qualitativo foi baseado nas orientações de Godoy, 1995B, Silva; Menezes (2005) que registram o papel do pesquisador como instrumento - chave. Conforme Ludke e Andre (2013), a investigação qualitativa tem como característica: em geral, ocorre no ambiente natural com coleta direta de dados e o pesquisador é o principal instrumento; os dados coletados são preferencialmente descritivos; tem foco no produto - "significado" que as pessoas dão as coisas e a sua vida; importância também está no pesquisador e; o método indutivo é o processo desenvolvido. Quando à escolha de investigação bibliográfica, os mesmos autores apontam para a busca do resultado não como o foco da abordagem, mas sim o processo e seu significado, ou seja, o principal objetivo é a interpretação do fenômeno objeto de estudo.

Para reafirmar o nosso compromisso com uma educação interativa, a BNCC nas competências gerais da educação básica defende que:

Compreender, utilizar e criar tecnologias digitais de informação e comunicação de forma crítica, significativa, reflexiva e ética nas diversas práticas sociais (incluindo as escolares) para se comunicar, acessar e disseminar informações, produzir conhecimentos, resolver problemas e exercer protagonismo e autoria na vida pessoal e coletiva. BNCC (2018 p.9)

Assim, se vê a importância de incorporar as redes sociais no que tange a leitura no currículo escolar dos educandos, uma vez que esses meios perpassam a sua realidade e estimula o protagonismo juvenil.

\section{Resultados e Discussão}

A leitura e a escrita no processo de ensino são primordiais, e por isso é preciso desmitificar que são apenas procedimentos de codificar e decodificar, pois como afirma Silva:

A leitura não pode ser confundida com decodificação de sinais, com reprodução mecânica de informações ou com respostas convergentes a estímulos escritos pré-elaborados. Esta confusão nada mais faz do que decretar a morte do leitor, transformando-o num consumidor passivo de mensagens não significativas e irrelevantes. SILVA (1987, p. 96).

Sendo assim, precisa-se através da leitura estimular o pensar crítico e por defendermos a linha interacionista de linguagem, entende-se que é na interação que os sentidos são construídos.

O educador tem um papel significativo no estímulo à leitura. Seu trabalho pode resultar em um novo leitor ou não, para a escola e para o mundo. Por isso é função do professor procurar e aplicar metodologias que possam "criar" e dar continuidade a uma nova gama de leitores, como afirma a autora Anjos (2012, p. 02) "A leitura engloba não só metodologias no âmbito escolar, mas faz parte do universo social na vida da criança de hoje e do cidadão de amanhã, que irá ocupar seu espaço na sociedade, de forma autônoma e crítica diante da realidade".

Conforme Koch e Elias (2006, p. 11) defende a leitura como "uma atividade interativa altamente complexa de produção de sentidos, logo essa afirmação articula com a proposta do vigente trabalho que é interagir todos os alunos e professor com suas indicações literárias.

Além do mais a BNCC (2018 p.70) "procura contemplar a cultura digital, diferentes linguagens e diferentes letramentos, desde aqueles basicamente lineares, com baixo nível de hipertextualidade, até aqueles que envolvem a hipermídia.)".

Tem-se uma prática em que todos os trabalhos em sala de aula, como apresentação, seminário, teatro, ou até mesmo gravação de vídeos partem de livros impostos em que os alunos não tiveram a chance de escolher e ao ler, mesmo gostando ou não, é obrigado a apresentar, pois foi uma exigência do docente para a conclusão do bimestre, por isso a proposta atual corrobora com o pensamento de que é necessário se ajustar as inovações e quebrar o paradigma que o ensino é construído apenas em quatro paredes e por isso repensar a forma de aprender e também de ensinar.

É preciso explorar o trabalho com a leitura concomitantemente com o seu contínuo, a produção de texto, na proposta 
da TIC aqui descrita. Conforme Antunes (2007, p. 70), a leitura é "uma atividade de acesso ao conhecimento produzido, ao prazer estético e, ainda, uma atividade de acesso as especificidades da escrita" desta forma, vemos a importância de se trabalhar a leitura deleite e consequentemente isso irá auxiliar na produção escrita do educando, permitindo um olhar mais reflexivo e crítico. Acrescenta-se também a oportunização da ampliação do repertório sociocultural e linguístico, novas experiências e momento de extravasar.

Irandé Antunes em seu livro Aula de Português: encontro e interação (2003, p.76) nos mostra possibilidades de aplicação de metodologias em sala de aula sem focar apenas no ensino tradicional, sem contextualização de uso, ela explora um viés que abarca a funcionalidade da língua, afirma ainda que há uma tríplice função na implicação da realização da leitura, sendo elas: "ler para informar; ler para deleita-se; ler para entender as particularidades da escrita".

Antunes (2003, p.77) afirma ainda que "a leitura envolve diferentes processos e estratégias de realização na dependência de diferentes condições do texto lido e das funções pretendidas. "

Ademais, Coenga também discorre sobre o desafio de desenvolver bons leitores ao defender que:

Formar bons leitores é um desafio para a escola e muitos professores. Muitos professores que atuam nas escolas primárias e até mesmo nas universidades se lamentam de que a maioria dos seus alunos lê mal, além de não saber escrever. Algumas explicações adequadas podem ser encontradas nos autores que descrevem a leitura como uma espécie de diálogo, de troca, de interação entre autor/texto/leitor. (Coenga, 2010, p. 69).

Isto posto, vimos que o professor na sua função de mediador deve conduzir a melhor opção para formar e cativar leitores, como já defendido anteriormente é preciso ter uma interação entre autor-texto-leitor.

Lajolo (2005, p. 10) ressalva que "é na escola que os alunos precisam viver as experiências necessárias para, ao longo da vida, poderem recorrer aos livros e à leitura como fonte de informações, como instrumento de aprendizagem e como forma de lazer".

Para acrescentar ao debate sobre o papel da leitura temos Manguel, em que defende:

(...) em cada caso é o leitor quem lê o sentido; é o leitor que confere a um objeto, lugar ou acontecimento uma certa legibilidade possível, ou que a reconhece neles; é o leitor que deve atribuir significado a um sistema de signos e depois decifrá-lo. Todos lemos a nós e ao mundo à nossa volta para vislumbrar o que somos e onde estamos. Lemos para compreender, ou para começar a compreender. Não podemos deixar de ler. Ler, quase como respirar, é nossa função essencial. (Manguel, 1997, p. 19)

A escola por se constituir de diferentes pessoas, pensamento, culturas, costumes e gostos é o palco ideal para a propagação de um marketing literário e a inter-relação entre os leitores, assim as redes sociais como um todo são as responsáveis por essa divulgação e entrosamento.

A educação vem passando por algumas atualizações, principalmente em relação ao uso da tecnologia, temos os mais variados recursos que podem ser utilizados em sala de aula e para isso precisamos estar abertos a mudanças, dado que a escola precisa comtemplar a demanda das tecnologias digitais da informação e comunicação (TDIC).

As tecnologias vieram para transformar as nossas práticas pedagógicas, Rojo afirma que:

As novas tecnologias, aplicativos, ferramentas e dispositivos viabilizaram e intensificaram novas possibilidades de textos/discursos - hipertexto, multimídia e, depois, hipermídia - que, por seu turno, ampliaram a multissemiose ou multimodalidade dos próprios textos/discursos, passando a requisitar novos (multi)letramentos. (Rojo, 2019, p. 26).

A discussão sobre multiletramentos não é antiga e de acordo com Rojo, o trabalho com:

Multiletramentos pode ou não envolver (normalmente envolverá) o uso de novas tecnologias de comunicação e de 
informação, mas caracteriza-se como um trabalho que parte das culturas e referências do alunado (popular, local, de massa) e de gêneros, mídias e linguagens por eles conhecidos, para buscar um enfoque crítico, pluralista, ético e democrático - que envolva agência - de textos/discursos que ampliem o repertório cultural, na direção de outros letramentos, valorizados (...) ou desvalorizados (...). Trabalhar com multiletramentos partindo da cultura de referência do alunado implica a imersão em letramentos críticos que requerem analises, critérios, conceitos, uma metalinguagem, para chegar a proposta de produção transformada, redesenhada, que implicam agencia por parte do alunado. ROJO (2009, p. 8-9)

Além disso, é preciso compreender que as TDICS são auxiliares aos processos de ensino aprendizagem em sala de aula, já que a cultura digital está propagada na atualidade, Rojo ainda afirma que:

O surgimento e ampliação de contínuos de acesso às tecnologias digitais da comunicação e da informação provocaram a intensificação vertiginosa e a (diversificação da circulação da informação nos meios de comunicação analógicos e digitais, provocaram mudanças significativas nas maneiras de ler, produzir e fazer circular textos na sociedade (ROJO, 2016, p. 19)

Por isso, precisamos compreender, conhecer e adotar essas mídias/redes sociais que perpassam o contexto da tecnologia digital para a realidade do ambiente escolar, é necessário entender que a tríade da educação está baseada em: Tecnologia, ensino e aprendizagem.

Para corroborar com a tríade, temos novamente a BNCC $(2018$, p. 499) reafirmando a importância do trabalho com a TDIC ao ter como umas das habilidades destinada ao ensino médio a de "explorar tecnologias digitais da informação e comunicação, compreendendo seus princípios e funcionalidades, e utilizá-las de modo ético, criativo, responsável e adequado as práticas de linguagem em diferentes contextos.

Na cultura digital ler é um acontecimento novo e também inovador, e a BNCC apoia a inserção das TDICS no âmbito educacional, pois o documento reconhece a importância da mudança das práticas pedagógicas, e a necessidade de inovação e incorporação da realidade do aluno com a comunidade escolar.

Precisamos compreender que na atualidade as redes sociais fazem parte do espaço de prática discursiva, o que de fato reflete de maneira direta e positiva no desenvolvimento do ensino em sala de aula. Isso porque necessitamos considerar as práticas sociais dos nossos alunos no momento da efetivação das aulas, pois é por meio de suas vivências sociais que a sua identidade escolar e cidadã é construída.

Assim, na busca incessante por leitores ativos e críticos, faz-se necessário que nas aulas de Língua Portuguesa, as redes sociais e todos os mecanismos tecnológicos que possibilitam a interação entre os sujeitos, sejam considerados como auxílio e suportes para o incentivo a prática de leitura, pois os alunos produzirão leituras que serão contempladas nas suas experiências cotidianas.

Nessa perspectiva Ribeiro afirma que:

E se houve um tempo em que o professor estava sempre adiantado em relação aos conhecimentos dos estudantes, ao menos em relação à maioria dos conteúdos, nas últimas décadas, o professor sente uma notável diferença de timing. A aceleração é maior, já que muitos conhecimentos e muitas ferramentas estão abertos a todos. Os estudantes sabem antes de nós, às vezes, embora quase nunca façam uso pedagógico do que sabem. Há, porém, professores adiante dos alunos quando o tema é tecnologia. A questão, então, não é “quem sabe primeiro". A questão é fazer uso significativo, com objetivos situados, das TICs. (Ribeiro, 2013, p.16).

Dessa forma, faz-se necessário que o docente faça uso das tecnologias nas suas aulas, a fim de possibilitar uma interação maior entre os discentes, conteúdos e o "universo" digital, o qual integra a vida da maioria dos nossos alunos. As tecnologias estão cada vez mais enraizadas na sociedade, e devido a isso, não compete mais a nós professores pensarmos e querermos trabalhar nas nossas aulas, sem o auxílio de uma tecnologia.

Nesse sentido, observamos que o Tik Tok é uma maneira interativa, moderna, e principalmente, estimuladora para que os nossos discentes despertem o hábito de indicar, gravar e explicar de maneira leve e objetiva sobre um livro, um poema, um 
conto ou qualquer outro tipo de texto que tenha realizado a leitura. Para que isso ocorra com qualidade, os docentes precisam entender que a tecnologia faz parte do processo de ensino e aprendizado da sociedade contemporânea.

Segundo Ribeiro (2007, p. 133), “[...] o leitor amplia seu leque de possibilidades de leitura à medida que entra em contato com esses suportes e gêneros reconfigurados, que por sua vez são híbridos". Sendo assim, compreendemos que o processo de leitura atrelado às redes sociais, mas especificamente ao Tik Tok, contribui com o aperfeiçoamento da aprendizagem e do pensamento crítico dos alunos, diante de diferentes gêneros textuais, pois eles conseguem perceber e associar as suas práticas discursivas, de acordo com as suas necessidades de comunicação dentro da sociedade. E tal fato, é de extrema importância, pois a aprendizagem perpassa das paredes da sala de aula.

Diante disso, percebemos que as tecnologias digitais é uma ferramenta indispensável para o desenvolvimento das aulas de Língua Portuguesa, bem como uma oportunidade inovadora e moderna que colabora com o desenvolvimento da habilidade de leitura em um contexto novo e desafiador dentro do contexto social contemporâneo.

O Tik Tok é um aplicativo que foi lançado em 2016, contudo seus acessos alavancaram em 2020 por conta do período pandêmico. É uma ferramenta que permite criar, compartilhar e postar os mais variados vídeos de duração máxima de 60 segundos.

Apoiado em Vieira e Silva (2019)

é fundamental promover um processo ensino-aprendizagem que leve o aluno a pensar, a pesquisar, a se entender como sujeito ativo no processo de cognição, como coautor do conhecimento. A sala de aula precisa, então, apresentar-se como um ambiente que fomenta a interatividade, a troca de informações, a produção de saberes. Vieira e Silva (2019, p. 16)

Afinal, hoje em dia é difícil quem não se rendeu aos encantos dessa plataforma, pois permite entretenimento, conhecimento, divulgação, ensinamentos, indicações e ainda dá espaço para que a escola faça um trabalho mais sério e crítico.

"O Tik Tok é o principal destino para vídeos móveis de formato curto. Nossa missão é inspirar criatividade e trazer alegria" (TIKTOK, 2020). Pensando nessa afirmação dos criadores do aplicativo, a proposta metodológica de ensino é voltada pensada em criatividade, inspiração, criação e recomendações, no caso de livros de diversos gêneros literários. Essa ferramenta é a ideal para divulgações dos livros pelos alunos dados que nela há várias possibilidades de criação, há palco para o aluno mais tímido como o mais desinibido.

A cultura do Tik Tok foi delineada para que seus usufruidores colaborem uns com os outros através de visualizações, curtida e compartilhamentos a fim de viralizar os vídeos de seus perfis. Observe na imagem os comandos de curtir, comentar e compartilhar grifados de amarelo, comandos esses que possibilita a propagação dos vídeos. 
Figura 1: Imagem da Interface do sistema Tik Tok.

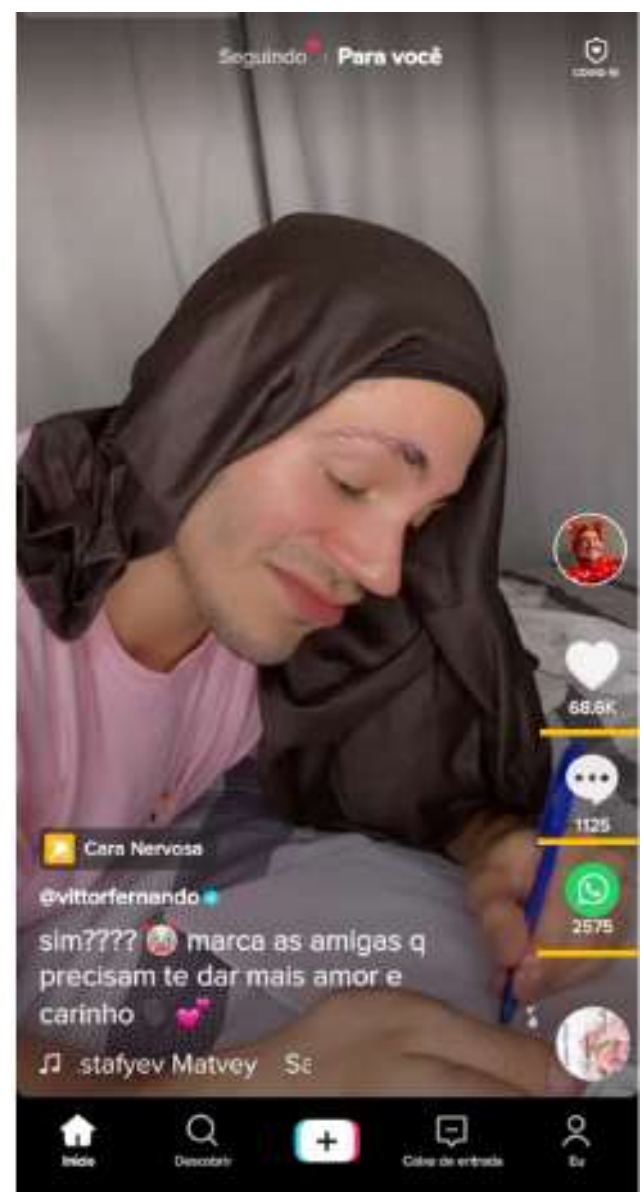

Fonte: Tik Tok.

O trabalho com o Tik Tok é uma potencialidade pedagógica através das mídias digitais, a ação de aprender, ensinar e estimular através de uma ferramenta que circunda a realidade estudantil, permite um ensino mais colaborativo e significativo. Na Figura 1 podemos ver a interface do Tik Tok e notar destacado de amarelo os elementos que compõem o aplicativo para interação e divulgação dos vídeos.

Consoante Freire (1996, p.47), "Ensinar não é transferir conhecimento, mas criar as possibilidades para a sua própria produção ou a sua construção", compreendemos então que a aprendizagem deve ser construída com experiências que estabelece relações com a ambiente em que o discente está inserido, ou seja, sua realidade e contexto social, salientando assim a importância do trabalho com o aplicativo. A pandemia trouxe uma reflexão sobre o uso de tecnologias em nossas práticas que provavelmente demorariam para ser aceita se estivéssemos em outro cenário, por isso a viabilidade de ferramentas, espaços virtuais e recursos estão sendo conhecidos, aproveitados e executados nesse momento de reformulação de metodologias e estratégias didáticopedagógicas.

Contudo, mesmo com adaptações, o foco permanece o mesmo que é engajar, tornar a construção de aprendizagem prazerosa e o aluno ser o protagonista e nos mediadores de ensino.

Os novos modos de produção são desafios para o corpo docente e a escola como um todo, pois geralmente o ensino tradicionalista, pautados em apenas regras, não permite uma interação entre autor-texto-leitor/produção de novo texto e o aplicativo TIK TOK como suporte midiático para uma aprendizagem interativa permite o diálogo, recomendações e ponto de vista, afinal professor e aluno são agentes de mudança. 
No eixo leitura a BNCC discorre que as práticas de linguagem que decorrem da interação ativa do leitor/ouvinte/espectador com os textos escritos, orais e multissemióticos e de sua interpretação, sendo exemplos as leituras para: fruição estética de textos e obras literárias; pesquisa e embasamento de trabalhos escolares e acadêmicos; realização de procedimentos; conhecimento, discussão e debate sobre temas sociais relevantes; sustentar a reivindicação de algo no contexto de atuação da vida pública; ter mais conhecimento que permita o desenvolvimento de projetos pessoais, dentre outras possibilidades. BNCC (2018 p.71)

Um modo eficaz de estimular e incentivar o jovem a leitura é atraí-lo, estimular e incitar a curiosidade a partir de recomendações de obras feitas pelos próprios colegas de sala, em que têm os gosto e apreciações parecidos, já que são da mesma faixa etária.

Desse modo, o uso dessa mídia permite a inserção dos estudantes com as práticas letradas a partir de ferramenta e meios que perpassa a sua vivência.

Rojo acredita que:

[...] a escola deveria partir do que a gente chama de repertório, e eles chamam de mundo de vida do aluno, ou seja, da cultura local que esse aluno traz para sala de aula que deve ser, não só valorizada, mas incorporada no tratamento dos objetos de ensino. Quer dizer, isso também é uma coisa a refletir, coisas que ele vê na mídia de massa, o que ele faz na internet e tal é para ser trazido para colocar em diálogo. Rojo (2012, p. 36)

Assim, a sugestão do trabalho com o aplicativo parte da observação que os jovens que frequentemente utilizam esse aplicativo para gravar vídeos cómicos, filosóficos, indicações de diversos produtos e coisas, imitação, instruções, dicas, desafios e etc., então porque não semear para os usuários e colegas de classes livros que fizeram a diferença em suas vidas?

A proposta metodológica utilizada é a Leitura Challenge, ou Desafio de Leitura, inspiração tirada dos blogs educacionais e grupos de professores de Língua Portuguesa do Facebook, com algumas adaptações de acordo com a realidade do grupo de educandos.

A ideia é dialogar primeiramente com os alunos sobre a proposta e fazer concessões se houver necessidade. É preciso deixar tangível para eles qual objetivo, orientações e possibilidades de gravações.

Segundo passo é deixar bem claro que a gravação do vídeo é sobre um livro que leram, gostaram e que estimaria que outros tivessem a chance de conhecer a história, indiferente de qual seja o gênero literário.

As regras para o Challenge são as seguintes:

o Challenge são as seguintes:

- Escolher um livro que recomenda;

- Gravar vídeo de no mínimo 30 segundos, se achar necessário poderá gravar mais um vídeo para explicitar o enredo da obra escolhida;

- Poderá fazer:

i. Dança

ii. Ilustrações

iii. Música/paródia

iv. Reproduzir cena marcante

v. Representar os personagens

vi. Resumir o livro de forma criativa

Segue abaixo as imagens de sugestões para divulgação da proposta metodológica, que podem ser divulgadas através do whatsapp, email, plataformas de ensino como o Google Meet, Microsoft Teams e etc. 
Figura 2: Proposta para ser trabalhado o Leitura Challenge.

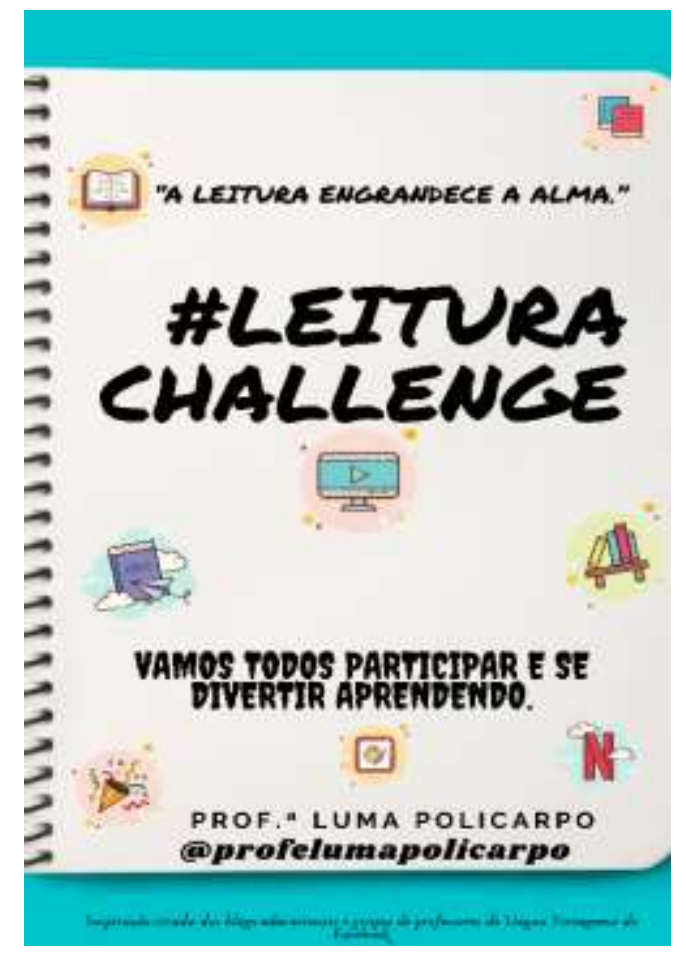

Fonte: Autores.

A Figura 2 é a chamada inicial para a participação do Challenge e serve para divulgação entre os educandos e até professores que desejam participar.

Figura 3: Imagem com as regras detalhadas do Challenge.

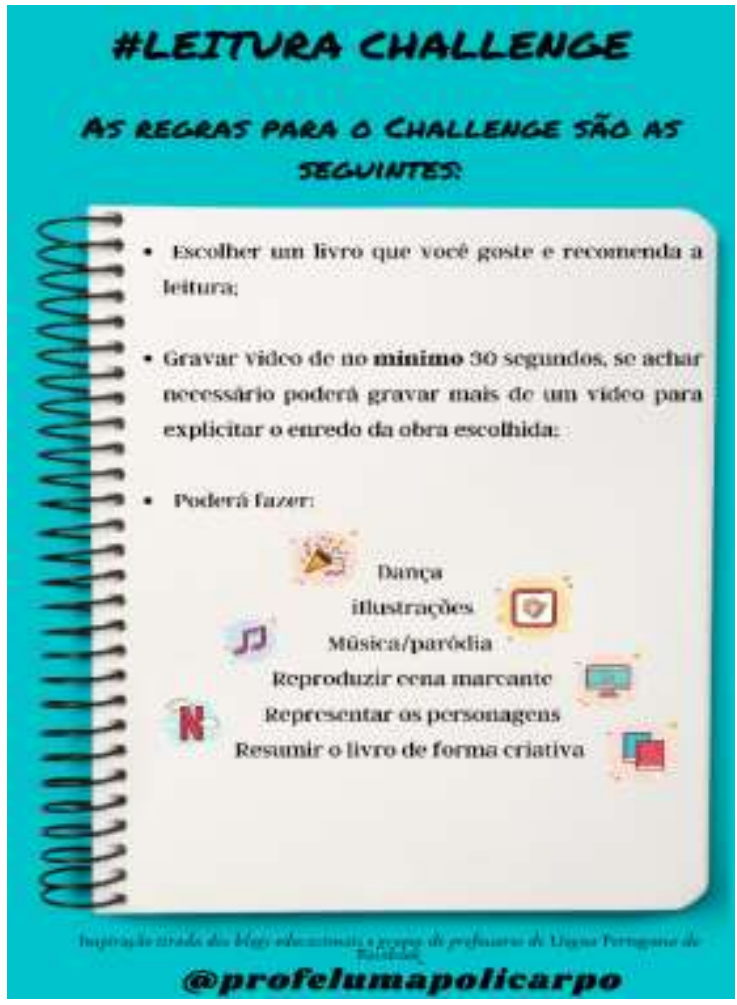

Fonte: Autores. 
A Figura 3 mostra as especificações de como deve funcionar a gravação do vídeo, possibilita aos alunos opções de como quer divulgar sua indicação literária.

Figura 4: Imagem com o objetivo do desafio.

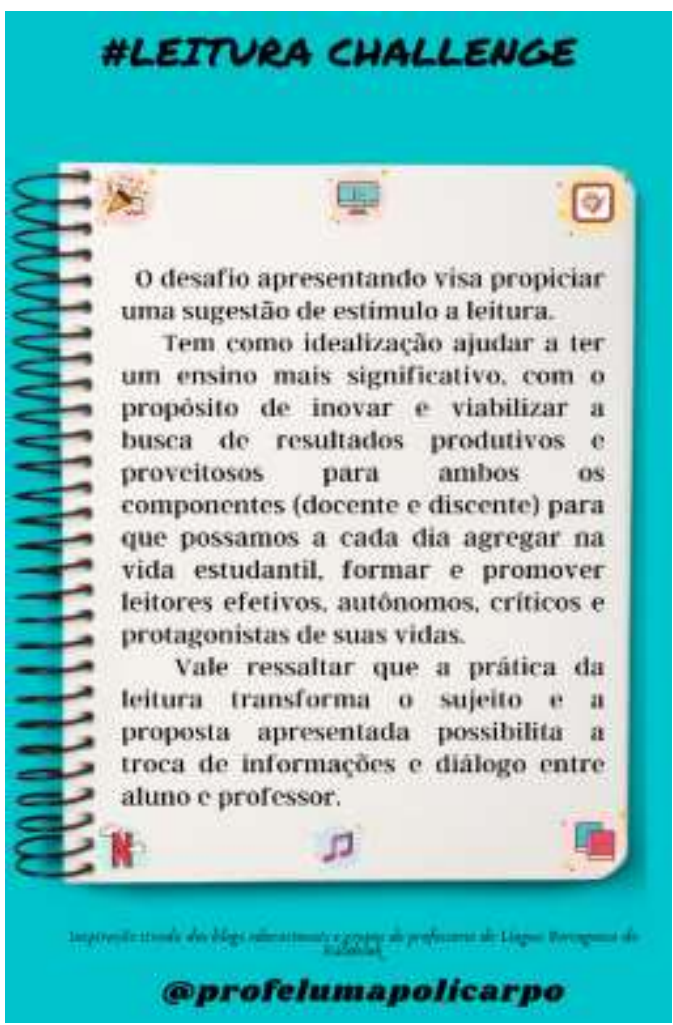

Fonte: Autores.

É importante que o educando saiba qual o objetivo da atividade que é proposta a ele, para que não tenha a falsa compreensão de ser um passatempo a gravação de vídeo em sala de aula, por isso a figura 4 é destinada a justificativa do planejamento metodológico.

Dessa maneira, torna-se trabalho do docente buscar renovações em suas práticas pedagógicas para que o conteúdo explanado possa atrair o adolescente que nesse caso é o incentivo à leitura, através de indicações dos colegas de classe. Antunes diz que o docente " que gosta do que faz, se empenha, elabora e executa seus planos de aula com carinho e afeição, tudo isso acarreta que o educando aprenderá com maior facilidade, respeitando a especificidade, e ajudando os demais colegas em sala de aula", e é nesse momento que a estratégia de ensino através do Tik Tok passa a ser uma ferramenta pedagógica, como afirma Luckesi (2000, p. 96) o que caracteriza o lúdico "é a experiência de plenitude que ele possibilita a quem o vivencia em seus atos".

Antunes (2003, p.127) afirma que" o leitor competente lê procurando sentidos, emoções, intenções, ditos e pressupostos “, posto isso evidencia um dos propósitos do professor de língua materna que é a leitura com significação e não obrigatória, uma leitura deleite e com fruição.

Kleiman ainda ressalta que

Quanto mais conhecimento textual o leitor tiver, quanto maior sua exposição a todo tipo de texto mais fácil será sua compreensão, pois o conhecimento de estruturas textuais e de tipos de discurso determinará, em grande medida, suas expectativas em relação aos textos, expectativas estas que exercem um papel considerável na compreensão" (Kleiman, 2009, p. 20). 
Portanto, compreendemos que o trabalho com o incentivo a leitura de variados tipos de textos, permite ao discente assimilar melhor o mundo a sua volta.

\section{Considerações Finais}

Considerado o objeto de estudo, a base teórica exposta, a metodologia, e os apontamentos realizados nesta proposta, pode-se afirmar que o trabalho com a leitura ainda se configura num desafio, contudo utilizar meios em que perpassam a realidade do educando se mostra um caminho de estratégia de leitura para atraí-los.

O desenvolvimento de estratégias de leitura deve ser viabilizado na escola com o objetivo de construir sentidos para os discentes e para os docentes.

O professor tem buscado, no cenário problemático que vivencia, várias ferramentas dispostas na internet. Assim, o uso do Tik Tok é um apoio aos processos de ensino-aprendizagem, pois possibilita estar dentro da realidade do alunado, além de que é apresentado um novo mundo da leitura viabilizado pela mídia/rede social no qual eles fazem a produção de conteúdo multimídia, com o propósito comunicativo definido que é indicação dos livros através da persuasão. Entende, nesta perspectiva, que não se produz texto somente com palavras.

Diante disso, o uso das tecnologias digitais como ferramenta que auxilia no desenvolvimento das práticas educacionais é de extrema relevância para que o processo de ensino e aprendizagem esteja relacionado de maneira direta às práticas discursivas e sociais dos nossos alunos, porque a leitura precisa ter uma significação para eles. Faz-se necessário que percebam a temática abordada no livro que fez a leitura em seu cotidiano, e principalmente no ambiente virtual, onde a maioria dos alunos passam horas conectados. A partir daí, construam suas ideias adaptando-as ao código que escolher.

Portanto, a prática de leitura nas aulas de Língua Portuguesa com o auxílio do Tik Tok irá colaborar de maneira positiva com interesse dos alunos em compartilhar as suas indicações e comentários sobre as obras que fizeram a leitura, contribuindo, assim, com o surgimento de novos leitores.

Tendo-se conscientemente uma leitura de "professor brasileiro", a necessidade de cursos para Metodologias Ativas é um recurso imprescindível para que a escola do Brasil melhore seu nível em todos os aspectos e em leitura principalmente. A pandemia exigiu que o professor desenvolvesse trabalhos em grupo e recorresse às tecnologias para desenvolvê-los.

Assim, novos trabalhos acadêmicos que discutam a prática do docente em sala de aula podem se constituir um suporte importantíssimo para apoio e desenvolvimento das aulas.

\section{Referências}

Anjos. L M. (2012). A importância da leitura no processo de alfabetização e o uso da biblioteca como espaço de construção do encanto pelo ato de ler. IX Seminário Nacional de estudos e pesquisas "história, sociedade e educação no Brasil”. Universidade Federal da Paraíba - João Pessoa.

Antunes, I. (2003) Aula de português: encontro \& interação. Parábola

Antunes, I. (2007) Uma análise de gramática muito aquém do texto. In: Antunes, I. Muito além da gramática: por um ensino de línguas sem pedras no caminho. Parábola.

Brasil. (2018). Ministério da Educação. Base nacional comum curricular. MEC. http://basenacionalcomum.mec.gov.br/.

Coenga, R. (2010.) Leitura e letramento literário: diálogos. Carlini \& Caniato.

Freire, P. (1996) Pedagogia da Autonomia. Saberes Necessários à Prática Educativa. Paz e terra.

Godoy, A. S.(1995B.) Introdução a pesquisa qualitativa e suas possibilidades. Revista de Administração de Empresas. 35(2), 57-63.

Koch \& Elias, V M. (2006). Ler e compreender: os sentidos do texto. Contexto.

Kleiman, A. (2009). Texto e leitor: aspectos cognitivos da leitura. Pontes.

Lajolo, M. (2005). Meus alunos não gostam de ler ... O que eu faço? Cefiel/IEL. UNICAMP. 
Research, Society and Development, v. 10, n. 13, e217101321119, 2021

(CC BY 4.0) | ISSN 2525-3409 | DOI: http://dx.doi.org/10.33448/rsd-v10i13.21119

Luckesi, C. (2000). O que é mesmo o ato de avaliar a aprendizagem. Revista Pátio, ano 3, n12.

Ludke, M.\&Andre, M. E. D. A. (2013) Pesquisa em educação: uma abordagem qualitativa. (2a ed.), EPU.

Manguel, A. (1997). Uma história da leitura. Companhia da Letras.

Ribeiro, A. E. (2007) Ler na tela - letramento e novos suportes de leitura e escrita. In: Coscarelli, C. V.; Ribeiro, A. E. (org.). Letramento digital: aspectos sociais e possibilidades pedagógicas. Ceale; Autêntica,

Ribeiro, A. E. (2013) Por que o computador on-line é bem-vindo no planejamento das nossas aulas? In: Ribeiro, A. E.; Novais, A. E. C. (Orgs.). Letramento digital em 15 cliques. Editora RHJ.

Rojo, R. (2009) Letramentos múltiplos, escola e inclusão social. Parábola.

Rojo, R. (2012) Pedagogia dos multiletramentos: diversidade cultural e de linguagens na escola. In: Rojo, R.; Moura, E. (orgs.). Multiletramentos na escola. Parábola.

Rojo, R. H. R. \& Moura, E. (2012) Multiletramentos na escola. Parábola.

Rojo, R. (2016).Escol@ Conectada: os multiletramentos e as TICs. Parábola.

Rojo, Roxane; Moura, E (2019). Letramentos, mídias, linguagens. Parábola.

Silva, E. Lucia \& Menezes, E. M. (2005) Metodologia da pesquisa e elaboração de dissertação. (4a ed.), UFSC.

Silva, E. T (1987). O ato de ler: fundamentos psicológicos para uma nova pedagogia da leitura. Cortez.

Vieira, F. M S. \& Silva, L. T. (2019) Redes Sociais: Possibilidades para o Desenvolvimento de Práticas Argumentativas. Editora Appris 